\title{
SÔBRE A METODOLOGIA DA CIEENCIA MODERNA EXPERIMENTAL
}

\author{
(Palestra proferida no Centro Acadêmico "Luiz de Queiroz")
}

\author{
F. G. BRIEGER
}

Se quizermos tecer algumas considerações sôbre a metodologia da ciência moderna, torna-se indispensável definir em primeiro lugar o que representa para nós uma "pesquisa científica". Uma pesquisa de petróleo, que tem por finalidade constatar se existe ou não petróleo numa determinada região, não é uma pesquisa científica completa. Uma pesquisa demográfica, isto é, um recenseamento no qual se acumulam dados sôbre c número de nascimentos, sôbre o número de mortes nas dife. rentes idades dos componentes da população, etc., também uria simples acumulação de fatos. Sòmente quando formulamos urna pergunta científica e empregamos os dados para achar a resposta, então entramos realmente na órbita da ciência. A obterição de dados e a constatação de fatos que representam apenas um trabalho científico preliminar, exigem um trabalho metodológico e às vezes bastante complicado, sendo necessário seguir certos processos e métodos característicos para cada ranc da ciência. Para formular uma pergunta e para tirar conclusões que podem servir como resposta, temos que usar um processo metodológico, mais complexo que já não é mais especín!- 
co, mas geral para tôdas as pesquisas. Estes métodos, que em parte são de ordem filosófica, são bastante velhos e são tão cunhecidns hoje que muitos cientistas não dão mais conta nem da slia evolução histórica nem dos seus princípios fundamentais. Eles nem sabem às vezes que a base metodológica do seu trabalho intelectual e dos seus experimentos foi criado há alguns mil anos pelos filósofos gregos e seus precursores.

Como uma das poucas lembranças da ligação entre as ciências experimentais e a filosofia, podemos referir-nos ao fato que em muitas universidades europeias, bem como em universidades quє adotavam a organização europea, encontramos êstes diferentes ramos da ciência reunidos numa "Faculdade de Filosofia". Nesta antiga estrutura universitaria, houve também uma profunda separação entre a ciência pura ou fundamental e a ciência aplicada.

As ciências médicas, agronômicas, de engenharia, etc., ficaram em Faculdades separadas, e sòmente as ciências naturais e fundamentais, como a química, física, as ciências biológicas, etc, ficaram juntas com a filosofia. Está desaparecendo porém, em nosso tempo, cada vez mais, a distinção entre ciência fundamental e aplicada, e ao mesmo tempo, as ciências experimentais se afastaram da filosofia. Muitos pesquisadores diriam hoje que nem há tempo e nem mesmo necessidade para estudos filosóficos. A metodologia cristalizou-se de fato numa forma que permitirá por muito tempo ainda a execução de pesquisas que ampliam os nossos conhecimentos fundamentais e abrem novos horizcntes para a sua aplicação. Porém é possível que, um dia, terminará esta era de pesquisas e então os cientistas terão que rever as bases filosóficas do seu trabalho para achar novos processos metodológicos. Não adianta porém deplorar no mc. mento a atual situação. A tendência inevitável no momento ó na direção de uma forte especialização exigindo trabalho de equipe, no qual cada pesquisador se considera responsável apenas por um setor de estudos bastante complexos em conjunto. Não está desaparecido o tipo do pesquisador antigo que sòmente estuda aqueles problemas que êle mesmo entende em todos os seus aspectos, mas o seu número está se tornando relativamente menor em comparação com o número cada vez maior de pesquisadores especializados com horizontes às vezes limitados.

Porém, mesmo assim, ou talvez justamente por causa disso, me parece de importância fazer um estudo sôbre as bases filcsóficas da metodologia atual, nas ciências modernas experimentais. 
Ncis tempos antigos, as escolas filosóficas da antiga Grecia puzeram em evidência o contraste entre o métcido indutivo e o método dedutivo. No primeiro, partimos de detalhes e, por sintese, chegámos a conceitos mais gerais; cada conhecimento nuvo nos induz fazer um passo para frente na abstração. No métcdo dedutivo, ao contrário, se parte de uma tese geral, deduzindo depois como se apresentarão os casos especiais.

O método dedutivo caiu muito em desprêzo por duas razões. En: primeiro lugar aumentou o cepticismo de um modo geral diminuindo sensivelmente o respeito pela autoridade, não se aceitando tão fàcilmente mais teses, formuladas a priori. Também teve efeito negativo o desenvolvimento exagerado de processos muito formais da dedução, chamados "silogisme". Nesta forma exagerada de lógica, partimos a) de uma tese geral e b) de uma tese mais restrita, para depois tirar conclusões sôbre um caso específico. E' bem conhecida a sequência lógica: Tese geral : "Todos os homens são mortais" - Tése específica : "Sicrates é um homem". Dedução: "Socrates é nortail" Mas igualmente são conhecidos os círculos viciósos em que o process:) sil('gístico pode terminar, e daremos um exemplo, variando um tema muito antigo: Tese geral: O Govêrno decreta que todus os homens são desonestos e mentirósos. Tese específica : O Govêrno é composto de homens - Primeira dedução : os homens do Govêrno são desonestos e mentirosos. -.. Segunda dedução. se os homens do Govêrno são mentirósos, a tese geral, fornulada por êles, não pode ser verdadeira, e o oposto deve ser a veráade. Assim chegamos a uma nova tese geral, na segundia fase de dedução: O Govêrno, ao decretar que todos os homens são desonestos e mentirosos, quer dizer implicitamente que êles são de fato honestos e verdadeiros Acrescentamos cie novo a tese específica: o Govêrno é composto de homens, e deduzimos assim agora que os homens do Govêrno são honestos e não mentem. Mas se isto fôr verdade, a tese inicial não podia ter sido uma mentira, mas sim a verdade, e com isso está fechad:) o círculo vicioso. Esta forma de raciocínio, de tese geral e tese específica, de tese e antitese, não mais parece um sistema lógico, mas sim uma acrobacia intelectual que pode ser continuada "ad infinitum", sem chegar a conclusão alguma. Porém, tais exemplos não podem servir para condenar o processo dedutivo em si mesmo, mas apenas os exageros do silogismo. Como veremos mais tarde, a dedução, partindo de uma tese geral ou específica, ainda tem um lugar de grande importôncia na metodologia científica, e forma uma parte integrante e indispensável da ciência experimental. 
O processo indutivo sofreu alterações profundas desde os tempos dos filósofos gregos. Max Hartmann, um dos poucos biólogos modernos que era um destacado experimentador, mas ocupou-se ao mesmo tempo com questões filosóficas, distinguiu na sua "Biologia Geral" dois processos indutivos, um empregado desd€ os tempos de Aristóteles até Bacon, e outro, mais moderno, idealizado por Galileu. $\mathrm{O}$ primeiro, a indução generalizadora, toma, como ponto de partida, observações avulsas e subjetivamente acumulados, quando a outra a indução exata exige dados experimentais e comprovados como material base, bem como uma comprovação final da tese formulada pela indução.

Para melhor explicar a diferença entre esies dois processos indutivos, e para mostrar que a mais antiga ainda tem grande aplicação, citaremos em seguida um exemplo, tirado de estudos em andamento no nosso laboratório, e referente a evolução filogenética das orquídeas. Partimos neste tipo de trabalho, de dados de duas fontes : sôbre a distribuição fitogeográfica atual das orquideas e sôbre os mapas climatológicos e paleogeográficos de periodos geológicos, e tiramos no fim por indução generalizadora as nossas conclusões.

Os dados fitogeográficos são em resumo os seguintes : a) as sub-familias possuem representantes no sub-trópico e trópico de todos os continentes; b) as tribus são, com poucas excepções, limitadas a região subtropical e tropical ou das Americas ou do veilho mundo; c) cêrca da metade dos gêneros tem uma distribuição generalizada ou nas Américas ou no velho mundo, quandn as demais são limitadas (endêmicas) em determinadas zonas. Em seguida vem o material paleogeográfico: a) Antes do miocene (parte média do terciário, cêrca de 30 milhões de anos antes do nosso tempo) o clima na terra era bastante quente e os Continentes Eurasiático e a América do Norte eram ligad's e cobertos por uma flora tropical e sub-tropical; b) na primeira parte do mioceno o clima tornou-se mais frio, separando-se as floras sub-tropicais e tropicais do novo e do velho mundo, quando ao mesmo tempo levantou-se do mar, a América Central, ligando o Norte com o Sul; d) na parte mais recente do terciário (miocene e pliocene) a distribuição do clima parece ter sido a mesma como hoje, mas a região geográfica, que nos interessa foi várias vezes separada em zonas por braços de mar ou de lagos extensos, sendo estas zonas quase idênticas áquelas que já mencionamos.

Juntando agora êstes dois elementos : os dados fitogeográficos e paleogeográficos, podemos reconstruir por indução a fi- 
logenia das orquídeas. Por exemplo, a fase evolutiva que corresponde as sub-famílias deve coincidir com a época do início do miocent ou com uma época anterior, onde os continentes eram ainda em ligação. A evolução das tribus deve corresponder ao primeiro período da separação paleogeográfica das zonas mencionadas, etc. $\mathrm{O}$ elemento comprovante destas induções consiste no fato que as zonas paleogeográficas e fitogeográficas coincidem e que a coordenação pela síntese indutiva é lógica e coerente. Mas o que é importante frizar consiste no seguinte : nãn existe possibilidade alguma de comprovar estas induçōes por qualquer experimento. A comprovação consiste sòmente na harmonia entre os elementos básicos, independentemente acuniulados. Se o resultado da indução tivesse sido ilógico e em desarmonia com parte dos dados, então a indução perderia o seu valor. Para usar termos mais de acôrdo com os métodos experimentais e estatísticos, poderiamos dizer : a probabilidade de encontrar tanta harmonia entre os elementos básicos da indução, escolhidos independentemente, seria mínima, exceto se existe de fato uma correlação real entre os elementos, e esta correlação é expressa na forma de conclusões induzidas.

Éste exemplo nos permite pôr em destaque as diferentes fases do trabalho: (1) Em primeiro lugar vem a acumulação de dados + de observações; (2) combinando e sintetizando por indução generalizada, chegamos passo por passo a (3) conclusões que formam uma hipótese. A comprovação inicial desta hipótese consiste apenas no fato que êle explica de uma forma homogênea todos os dados e observações, acumulados na primeira fase do trabalho. Uma comprovação posterior e mais ampla pode obter-se acumulando novos dados e mostrando que êles estão também de acôrdo com a hipótese anteriormente formulada. Se o conjunto de dados torna-se muito grande, fi. cando as exceções pouco frequentes, então a hipótese transforma-se Jentamente numa teoria.

Os exemplos mais conhecidos dêste método são as teorias da evolução, como elas eram formuladas por Darwin e Lamarck. Depois de colecionar amplo material em suas viagens e no trabalho de laboratório. Darwin sintetizou todo êste material e foi induzido finalmente a formular uma hipótese generalizada sôbre a evolução: a evolução se deve ao acúmulo de pequenas varjações hereditárias, que aparecem acidentalmente e sem direção alguma, sendo que a seleção natural ou a "luta pela vida" determina a direção da evolução. Lamurck, trabalhando nos museus da França e recebendo material de todos os cantos do mundo, foi induzido a formular outra hipótese : os sêres vivos, plantas e animais, se transformam lenta, mas constante- 
mente $\epsilon \mathrm{m}$ harmonia com as necessidades da sua vida, e estas transformaçōes, num sentido de uma adaptação cada vez mais perfeita, se tornam hereditárias, depois de adquiridas pela primeira vez. As teses de ambos os autores têm em comum a conclusão que existe uma evolução dirigida, mas elas divergem profundamente a respeito da força diretriz: adaptação direta por mein da hereditariedade de caracteres adquiridos ou adaptaçãci indireta em consequência da seleção natural contra os caracteres desfavoráveis. Ambas as hipóteses, apesar de serem contraditórias, eram de acôrdo com os fatos então conhecidos, e a diferença constava em divergência do trabalho ináutivo $\mathrm{N}:$ o estando ainda reconhecido, como método superior de pesquisa, a realização de experimentos cruciais, a luta científica :imitou-se durante muitos anos a reunir um número cada vez maicr de fatos que os diferentes autores achavam, subjetivamente serem mais em favor de uma ou outra hipótese. A discussão das divergências passou mesmo em parte para o campo da filosofia e de especulação metafisica.

Não se podia proceder de outra forma em tempos nos quais as ciências naturais foram separadas em dois grupos: as ciências exatas como físicas e química, que empregaram o método experimental e a indução exata, e as ciências descritivas, como a bctânica e zoológica, que usavam apenas a indução generalizadora. Hoije porém a situação mudou profundamente. As ciências kiclógicas apezar de não poderem prescindir do método descritivo e da indução generalizadora, como vimos acima, aplicam. sempre quando possível, o método experimental e exato.

Como um dos primeiros cientistas, que empregou na biologia o método experimental, podemos citar Gregor Mendel. Não é bem claro, em todos os seus aspectos, como e porque êle iniciou os seus trabalhos genéticos como também parece bastante abrupto o fim dêstes estudos. Devemos porém supor que êle partiu de observações acidentais e empíricas, as quais induziram-no a executar experimentos exatos, cruzando plantas de ervilha, feijão, petúnia e outras mais, e estudando em que proporções apareceram os tipos paternais nas descendências. Assim, observações acidentais e empíricas induziram-no (indução generalizadora) a formular uma hipótese de trabalho que permitisse prever o que deveria acontecer num experimento. Mendel limitou-se em geral de verificar as segregações nas descendências obtidas por autofecundação. Baur introduziu mais tarde um teste crucial : o retrocruzamento dos híbridos para o pai recessivo que, além de dar proporções mais simples que facilitam a análise estatística, serve como prova da 
corıstituição genética postulada tanto dos pais como dos descendentes Sintetizando os dados do experimento, por indução exata, êle poude decidir que êstes resultados estavam de acôrdo com a hipótese provisória.

O elemento novo do processo consiste em que êle vae além da formação de uma hipótese pela indução generalizadora. Exige-se desta hipótese que ela permita fazer previsões e que estas previsões possam ser submetidas a comprovação experimental. Assim entra em jôgo de novo a dedução, pois evidenternente a previsão a que fizemos referência, consiste numa dedução: decuzimos, partindo da hipótese provisória, o que deveria acontecer num caso especial. Temos então aquí o princípio geral da dedução: partindo de um caso geral (a hipótese provisória) se deduz o caso especial (o provável resultado do experimento). Formulamos ainda, partindo de dados empiricamente acumulados e por indução generalizadora uma hipótese provisória, e terminamos com uma hipótese definitiva, aproveitando os dados do experimento e usanúo a indução exata.

Com cstas explicações gerais estamos agora preparados para pôr em evidência as diferentes fases de uma pesquisa experimental, bem conduzida :

EMPIRISMO

1) Acumulação de dados, de descrições, etc.

INDUÇÃO GENERALIZADORA

2) Formulação de uma hipótese provisória ("working hypothesis").

DEDUÇÃO

3) Planejamento de um experimento para comprovar a hipótese.

COMPROVAÇÃO EXPERIMENTAL

4) Execução do experimento

5) Análise do experimento

INDUÇÃO EXATA

6) Resultado do experimento, que pode ser :

$\begin{array}{ll}\text { a) Concludente, aceitando } & \text { b) Não concludente }\end{array}$ ou rejeitando a hipótese

Faremos em seguida algumas observações sôbre cada uma das fases da pesquisa, segundo o esquema dado acima: 
1) Sendo a acumulação de fatos, dados, descrições, etc., um trabalho puramente empírico, não é possível estabelecerem-se regras sôbre o procedimento necessário e mais vantajoso.

2) $\mathrm{Na}$ formulação da hipótese provisória devemos observar certas regras, que podem ser resumidas da forma seguinte: a) a hipótese não deve estar em contradição a fatos seguramente estabelecidos e nem a hipóteses já aceitas e baseadas em fatos comprovados, mas ela pode estar em contradição com conccitos de naiureza especulativa e não comprovados por fatos. Porém hipóteses muito espectaculares raramente corretas podem ser mais tarde mantidas. Entre as grandes descobertas muitas delas começaram com trabalhos aparentemente muito simples e de pouca importância geral.

b) A hipótese deve ser a mais simples possivel, não exigindo hipóteses auxiliares. A necessidade de acrescentar hipóteses auxiliares é quase sempre um sinal que alguma coisa estava errada na abstração indutiva ou que fatos importantes foram esquecidos, ou ainda que outros erros ou omissões ocorreram. tal.

c) A hipótese deve permitir a sua comprovação experinen-

Para melhor explicar a natureza destas exigências, citaremos dcis exemplos da ciência moderna :

Todos conhecem a grande importância que os medicamentos antibióticos têm hoje na medicina, como a penicilina, a streptomicina, a aureomicina, etc. Como foi então que Flemming chegou a fazer descoberta do efeito da peniciliua, descoberta esta que era a base dêste novo ramo de estudos científicos ? Quando um bacteriologista pretende estudar bactérias ou outros micronrganismos, êle os cultiva em caixinhas de vidro que contêm uma geléia com soluções nutritivas e nas quais êle planta (inocula) a bactéria de tal forma, que só esta bactéria seja presente Porém acontece frequentemente por falta de cuidado, ou quando as caixinhas de vidro (placas de "Petri") näc fecham muito bem ou por outra razão qualquer, que uma outra bactéria ou um fungo invade a cultura. Em tais culturas contammadas pode acontecer muitas coisas : os dois microorganismos podem simplesmente crescer em conjunto, sem interferir um com outro, êles podem se repelir de modo que cada um ocupa uma parte da geléia de cultura, mas ás vezes também se observa o seguinte: o invasor progride constantemente e as bactérias da cultura desaparecem como se fossem dissolvidas 
por um ácido. Apezar da frequência de observações desta naturezd, ninguem dava a elas importância e costumava-se eliminar simplesmente as culturas contaminadas, consideradas como sem iriteresse algum e até como perda de tempo e de material. A descoberta de Flemming consistiu então no seguinte : Ele lembrava-se de tais observações em culturas de bactérjas, contaminadas por fungos, e, usando a sua inteligência, foi in. duzido a formular uma hipótese de trabalho, extremamente simples : certos fungos devem ser capazes de produzir substâncias, solúveis na água da geléia de cultura, e que tem a capacidade de matar e digerir bactérias, sendo assim talvez substâncias que possam ser usadas como medicamentos em doenças causadas por bactérias. A simplicidade da hipótese de trabalho não pode ser mais evidente. Ela não está em contradição rom qualquer cutra hipótese ou com fatos, pois era plenamente conhecido que as células dos fungos, como de outros organismos, produzem substâncias que sáem para fora e são solúveis em água. Também se sabia que células podem produzir substâncias que matan bactérias, pois caso contrário nenhum organ'smo poderia zesistir a infecções ou doenças causadas por bactérias. Finalmente a hipótese é fácil de ser comprovada, pois basłava cultivar furigos em soluções nutritivas, para depois verificar se estas soluçoes adquiriram a propriedade de matar bactérias. Flemming não recebeu o prêmio Nobel por ter formulado uma hipótese espectacular, mas por ter sido capaz de ter formulado uma hipótese, de fato muito simples, e depois mostrada mas que abriu um grande campo de pesquisas novas ? de grande aplicação prática na medicina.

Citaremos outro exemplo, desta vez da Genética. Sabia-se há muito tempo que ocorrem em todos os organismos alteraçŏos hereditárias, chamadas mutações. Elas são em geral raríssimas e assim não permitem um estudo sistemático das suas causas. Muller partiu, assim de uma evidência negativa. Se as mutações são raras, então as suas causas, desconhecidas ainda, devem ser raras também, talvez de uma natureza muito extrema e extraordinária. Revendo os agentes químicos ou físıcos que podiam ser úteis, êle escolheu, para estudos experimentais, os raios $\mathrm{X}$, e postulou que os raios $\mathrm{X}$ seriam capazes de provocar mutações. De novo a tese era em nada espectacular, não estava em contradição com qualquer fato conhecido e era simples de ser comprovada ou rejeitada. Ninguem previa na época que o auior, $7:$ Muller seria 25 anos mais tarde considerado com o prêmio Nobel, devido a grande influência que a descoberta dos raios $X$, como provocadores de mutações (mutagen) teve sóbre 
os nossos conhecimentos em geral, para os estudos sôbre o cancer e sôbre a evolução.

3. Terminada a segunda fase do trabalho, o pesquisador tem agora o caminho livre para planejar o seu experimento com n fim de comprovar a hipótese provisória que acaba de formular. Torna-se assim necessário que êle saiba deduzir, com bastante clareza, os casos especiais que serão objeto do experimentก. Por exemplo, um pesquisador chegou a conclusão que uma plinta precisa de adubação fosfatada. Agora êle tem que resclver o caso especial que será objeto de experimento, e assim escoIher a forma e dosagem da adubação fosfatada a serem aplicadas. Não podem ser formuladas regras, a respeito, mas deve-se lembrar que muitos experimentos já foram perdidos, pois o pesquisador não soube definir com bastante clareza a finalidade especifica do experimento.

Citaremos como primeiro exemplo a experimentação agrícola que visa determinar a melhor adubação de uma determinadat cultura. Podemos distinguir dois tipos de experimentos : c primeiro serve para verificar se um determinado solo precisa de elementos químicos ou não, e o segundo, para determinar qual o natureza e a concentração de adubo mais apropriado. No) primeirc caso bastam em geral experimentos simples, do tipo denominado por R. A. Fisher "NPK" nos quais temos três pares de tratamentos; com tôdas as combinações: com ou sem azotr (N). com ou sem potássio (K), com e sem fósforo (P). Porém para determinar a quantidade necessária de um adubo, torna-se necessário executar experimentos mais complexos com três ou mais dosagens de adubo, para achar finalmente uma curva de rendimento.

Ern experimentos sôbre melhoramento, onde postulamos que entre numerosas variedades, raças ou tipos, existem alguns melhores para a lavoura, também podemos distinguir dois tipos do experimentos: um primeiro que visa separar as melhores variedades, as médias e as pióres; para depois executar novo experimento, sòmente com as primeiras, a fim de verificar com maior rigor qual a melhor variedade. Dificilmente os dois experimentos, um extensivo e outro intensivo, podem ser realizados ao mesmo tempo.

Formulado o objetivo do experimento segue-se imediatamente a escolha do plano experimental, e frequentemente os dois passos não podem ser separados, pois escolhendo o objetivo entre numerosas possibilidades, devemos vêr ao mesmo tempo se um experimento é exequível ou não. tos:

Como regras gerais podemos destacar pelo menos três pon- 
a) em primeiro lugar deve ser excluido, ao máximo possível, o fator subjetivo, chamado pela escola anglo-americana o "bias". Para o leigo talvez êste ponto pareça de pouca importância, mas o cientista experimentado sabe qual a dificuldade de distinguir de um lado o "bias", isto é, o julgamento pre-concebido e demásiadamente subjetivo, e de outro lado, o julgamento objetivo inđoispensável. Objetividade é uma arte que se aprende sòmente com a prática, apesar que muitos pesquisadores sempre se julgam "muito objetivos". Porém não se deve ir ao outro extremo eliminar todo o julgamento ou raciocínio do pesquisador para excluir o "bias". O cientista também não é um executor mecânico do experimento.

b) Em segundo lugar devem ser excluidos, isto é, mantidos constantes, todos os fatôres que possam influenciar o experimento sem serem visados pelo mesmo e que podem ser denominados "fatôres secundários". Isto torna-se em geral fácil na física e química, mas na biologia, na agronomia ou medicina onde trabalhamos com sêres vivos, a situação é bem diferente. Cada indivíduo tem a sua história a sua vida antes do experimento e a sua herança, e assim diferentes indivíduos podem cornportar-se levemente ou mesmo fortemente diferentes durante o experimento. Nem sempre podemos realizar experimentos em condições bem controláveis do laboratório, pois temos que trabalhar no campo experimental, no estábulo ou no hospital. Assima a observância da exigência da "constância dos fatôres secundários" nem sempre pode ser completamente satisfeita na prática.

c) Pará reduzir o "bias" e para compensar a inconstância de fatures secundários torna-se frequentemente necessário recorrer-se aos métodos da estatística analítica.

Antigamente julgava-se que o único meio para eliminar variaçōes acidentais, causadas por fontes de variação incontroláveis e secundárias, consistia em aumentar o número de observaçōes e assim do tamanho do experimento. Este princípio "dis grandes números", pelo menos aparentemente correto do ponto de vista da estatística, traz consigo porém quase sempre sérias consequências. E' já dificil manter constantes as condições de um experimento limitado e pequeno; mas esta dificuldade se torna maior ainda, se aumetarmos o volume dos trabalhos experimentais. Por exemplo, em experimentos égrícolas pode ser relativamente fácil achar áreas de uns poucos metros quadrados com solo bem uniforme; porém quando precisarmos de muitas dezenas de metros quadrados, a escolha torna-se difícil. Pode-se fazer uma compensação de pequenas manchas e irregularidades do solo, mas corremos sempre o risco que nu- 
ma área maior incluimos uma "mancha" muito diferente do resto.

R. A. Fisher introduziu dois novos princípios que revolucionaram a técnica experimental : o princípio das repetições completas e o da distribuição de acaso ou da randomisação. Segundo o primeiro, considera-se mais vantajoso executar um maior número de pequenos experimentos, idênticos em seus detalhes de modo que êles representem repetições, ern vez da realização de um único experimento grande. $\mathrm{O}$ segundo princípio referese a sequéncia em que faremos os nossos estudos que pode ser sistemáticc ou acidental. Assim, em experimentos agrícolas, podemos dispor os tratamentos ou variedades, a serem comparadas, em ordem sempre idêntica, isto é, segundo um sistema; em experimentos químicos podemos também escolher uma ordem prèviamente fixada das análises a serem feitas. Porém Fisher mostrou que a "desordem" ou a sequência acidental tem grandes vantagens.

O planejamento básico, idealizado por êste cientista foi denominado: o método dos "blocos ao acaso" (random blocks). Mais tarde os pesquisadores idealizaram outros planejamentos, denıminados quadrados latinos, quadrados grego-latinos, planos fatcriajs e semi-fatoriais com confundição, látices simplés e cumplexcs, etc. Os estatísticos visam em geral um aumento do que se chama a "eficiência estatística", porém atribuem menos consideração a eficiência experimental, agrícola ou biológica.

d) Em último lugar teremos que citar mais um ponto de grande importância. O planejamento do experimento deve ser feito de tal forma que outros especialistas possam repetir o experimento, para a sua verificação.

4 e 5) Sôbre a execução do experimento e sôbre a análise dns dados obtidos, não precisamos tecer considerações nesta publicação, por se tratar de detalhes essencialmente técnicos. Porém quero lembrar um ponto importante. A parte da análise estatística, chamada "análise da variância", representa apenas uma parte de trabalho para a qual $R$. A. Fisher desenvolveu o método básico, mas que não dispensa a análise final detalhada que em parte aproveitou métodos modernos, mas também processus de estatística clássica.

6) Chegamos assim na fase final do experimento que é a mais importante, e consiste de um trabalho de abstração. Sintetizando os dados do experimento e os resultados da análise, temos que chegar a conclusões finais. Em primeiro lugar deveruos responder, se o experimento ere scncluàent,e ou não. 
No caso de um expeririento não ser concludente, devemos reconsiderar criticamente todos os passos do experimento, desde a hipótese provisória, o rlanejamento do experin_ento, a sua execução e análise, para descobrir se há uma possibilidade de modificar o planejamento de tal forma que se justifique uma repetição, introduzindo alterações que aumentam a probabjlidade de se chegar a conclusões finais definitivas. Repetir simplesmente um experimento, sem alteração alguma, pouco se reccmenda e raramente dá resultados satisfatórios.

Se porém um experinı nto termina coin munclusões defiriiivas, pode acontecer uma de duas coisas : a hipotese de trabalho foi comprovada ou rejeitada.

Devemos lembrar agora que em muitos casos fazemos experimentos para mostrar propositadamente que uma hipótese de trabalho é errada. Mencionámos acima (3) que uma hipótese de trabalho deve permitir organizar experimentos decisivos, mas de outro lado, existem hipóteses de trabalho que não permitem tais previsões. Por exemplo, em estudos de genética, acontece frequentemente que temos razão de supor que certos caracteres não seguem as leis de Mendel, mas não sabemos quais as regras excepcionais que devem ser aplicadas. Assim formulamos inicialmente uma hipótese que esperamos seja erracia: que os caracteres seguem as leis de Mendel. Agora podemos planejar um experimento, pois podemos prever o que aconteceria, caso houvesse uma segregação mendeliana normal. Comprovando que esta hipótese é errada, temos certeza de que se trata de uma excepção. Citaremos outro experimento agricola, sòbre os efeitos de adubações. Esperamos por exemplo que uma adubação aumente a produção, mas não sabemos corrio diferentes adubos, e dosagens dos mesmos, afetarão a produçăo 1aão podendo-se porisso fazer previsões. Então partimos da h1pótese oposta que a adubação não terá efeito algum, e, desprovada esta espectativa, temos provado automáticamente que houve efeito positivo da adubação.

E' interessante notar que quase tôda a análise estatística se baseia neste princípio da inversão da hipótese provisóicia. Sempre quando estudamos variáveis, existem auas possibilidades : a variação ou é acidental ou ela é sistemática, isto é, ela pode ser atribuida ao acaso ou a fontes de variação, que podemos sistematizar e controlar. Mas, poder controlar uma fonte de variação, não significa que podemos fazer previsões sôbre os seus efeitos. Voltando ao exemplo de um experimento sôbre adubações, depende de nós se aplicaremos ou não adubos e em que dosagens, mas não sabemos inicialmente nada sôbre o efeito das adubações sôbre a produção. A variação acidental ou de 
acaso, de outro lado, pode ser definida de foram matemática. Podemos supor que existem um sem número de fontes de variação que dão, cada uma, efeitos apenas pequenos e que ou se acumulam ou se anulam mutuamente. A matemática nos ensina como tratar um conjunto de tais efeitos, infinitamente frequentes, mas ao mesmo tempo infinitamente pequenos e que podem ter sinais positivos ou negativos, iguais ou opostos. Com a ajuda de fórmulas matemáticas podemos então calcular todos os detalhes da variação de acaso, o que não seria possível, como já dissemos, no caso da variação sistemática. Assim a análise estatística permite sòmente determinar, se tôda a variação pode ser atribuida ao acaso ou não. Em vez de provar que as fontes de variação sistemática causam um excesso de variabilidade, tentamos desprovar a hipótese que tôda a variação era apenas causada pelo acaso, pelas fontes incontroláveis, inherentes de cada experimento. $R$. A. Fisher denominou esta hipótese a "null hipotesis", pois postula que a variação sisıŁemática fosse nula.

Aplicamos de fato em todos êstes casos um princípio, bastante antigo, da lógica : a comprovação de uma tese, partindo da hipótese contrária.

Terminamos êste breve resumo, no qual mostrámos a profunda influência do método científico moderno, mesmo nas ciências experimentais, pelos princípios filosóficos e de lógica. Conceitos conhecidos há centenas de anos ainda hoje estão em pleno uso. Como já dissemos no início, a ciência experimental moderna que aparentemente é tão afastada da filosofia, emprega processos, discutidos desde os tempos de Aristóteles, e que são do domínio da filosofia e lógica. 